\title{
Computer support in statics
}

\author{
Katarína Tvrdá \\ Slovak University of Technology, Faculty of Civil Engineering, \\ Radlinského 11, 81005 Bratislava \\ Slovakia
}

Received: March 20, 2021. Revised: September 23, 2021. Accepted: October 7, 2021. Published: October 22, 2021.

\begin{abstract}
Nowadays new subjects are implemented into education process, for the sake of the support of existing profile subjects at the technical universities. The elaboration of assigned tasks on individual subjects is demanding and time consuming and therefore a subject is created, which facilitates the solving of the assigned tasks. The subject Computer support in statics tries to show the base of working with freely available programs such as SMath studio and Excel, which allow creating own user's algorithms based on the experience gained from this subject. While elaborating the tasks from statics and elasticity, a student utilizes the knowledge gained in the mathematics and physics courses. Followingly, the knowledge from engineering statics and elasticity theory are further utilized in subjects like concrete structures or steel and wooden structures. This paper performs a computation in software Smath studio. Students confirm their theoretical background, they can follow the computation and followingly can better understand the behaviour of the structure subjected to the load.
\end{abstract}

Keywords - simple beam, cross-sectional forces, displacements, trapezoidal loads, algorithms in SMath studio.

\section{INTRODUCTION}

when designing any structure or artifact, the static $\mathrm{W}_{\text {point }}$ of view of the issue has to be taken into account, as well. This has only been assessed empirically for millennia. Then, the pioneer static calculations appeared in the Middle Age, but only from the 18th century (Navier, Mohr, etc.) we can speak realistically about the static calculation of building structures.

Alongside with the development of calculation methods, the demand for onward knowledge and experience dissemination arose. Later on, the schools and universities replaced the original guilds of wandering freemasonry masters. The students gained structural and static knowledge at the level of the period at these schools and universities.

First, the calculations were performed manually, afterwards, with the advent of computer technology; various commercial programs (ANSYS, NEXIS, Scia Engineer, R FEM, FIN EC, ADINA, FEAT, etc.) approved their ability to solve static tasks. These software tools can be used in the pedagogical process, in engineering practice, but also for scientific purposes (in the field of statics, dynamics, foundation of structures, stability tasks, safety, stochastic assessment and many others). Many publications were published in the given topics [1-10].

Since current structures tend to be higher and more slender every year, namely the theory complexity and computational standard go forward quickly. Accordingly, the teaching of the students has to go in line with this process.

Likewise in Slovakia - since the beginning of teaching at the former Slovak University of Technology, the teaching of statics subjects was carried out by using of classical methods. These methods gave students a solid mathematical background, but due to the calculation difficulties, each student recalculated one example for each issue, and due to lack of time, he did not have the opportunity to vary variables, boundary conditions, or load.

With the advent of computer technology (approximately from the 90s of the last century), the teaching methodology shifted to the calculation of problems of structural mechanics via computers - mainly using the FEM application.

The student could change the boundary conditions, the load, but the whole derivation, programming and calculation were performed beyond the student. Hence, he could understand the results dependence on the inputs; however, the theoretical part remained a black box for him.

In this paper, I want to share the experience with such 
a calculation in the $N$ subject Computer Support in Statics. Student learns the theoretical foundations, practically sees the calculation, but this calculation is so fast and flexible that he can understand the causes of dependence of the result on changing inputs.

\section{SUBJECT -COMPUTER SUPPOT IN STATICS}

Computer support in statics is an accredited optional subject at the Faculty of Civil Engineering Slovak Technical University in Bratislava.

This course arose from the requirements of students to better understanding the principles of statics, flexibility and other technical subjects taught at technical universities. The aim of the course is to consolidate and deepen the knowledge they acquire during their studies. The student will gain the basics of working with a computer, can use computer support in solving of team and individual projects in the field of statics and construction. The output of the course is the creation of their own engineering calculations of static tasks in the environment of the program SMath studio [11] (free alternative of the Mathcad), or in the Excel.

The syllabus of this subject is following:

- installation, start-up and acquaintance with the SMath program workspace, basics of program control

- basic arithmetic operations

- basic built-in mathematical functions

- matrices, vectors and operations with them

- custom functions and their rendering in 2D

- introduction to programming

- solved examples from the field of statics

- getting acquainted with the program workspace

Excel, the basics of program control

- basic arithmetic operations

- solved examples from the field of statics

In this paper, we will deal only with the last issue of this course and solving examples from the field of statics. The following chapters present the theoretical foundations for solving of the problem, as well as the outputs from the program SMath studio, which can be created by the student, based on the experience already gained in the programs.

\section{THE TASK - SIMPLE BEAM WITH PLANAR LOAD}

Let us consider a simply supported beam loaded with an external load, Fig. 1. As a result of this load, internal forces are generated in the beam, as plotted in Fig. 2.

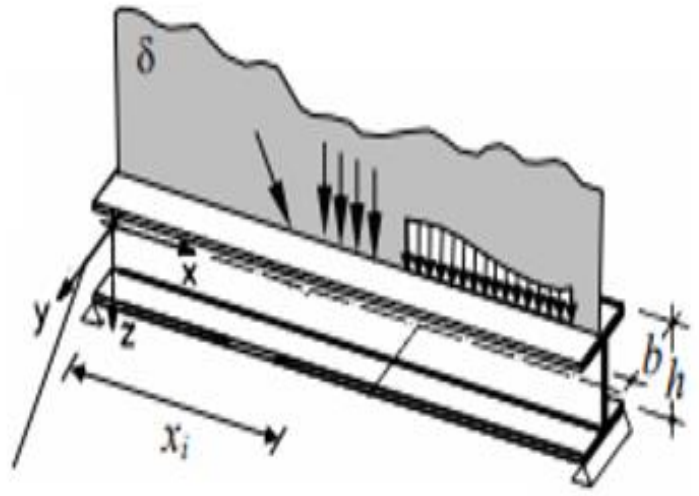

\section{global coordinate system}

Fig. 1 Beam with planar load

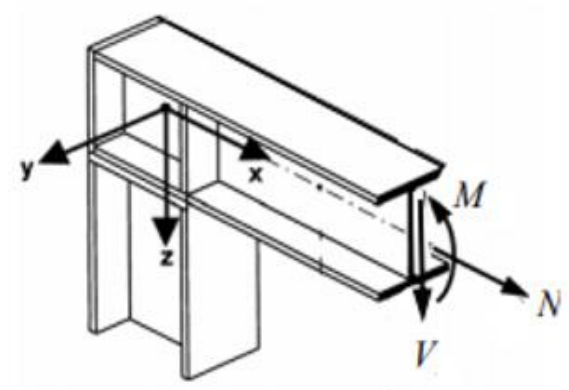

Fig. 2 Cross-sectional forces in a beam

An analysis of this beam may be calculated as follows:

- calculation of reactions

- calculation of normal forces $\mathrm{N}$

- calculation of transverse forces $\mathrm{V}$

- calculation of bending moments M.

The common sign convention in the calculation of internal forces [12] is shown in Fig. 3.
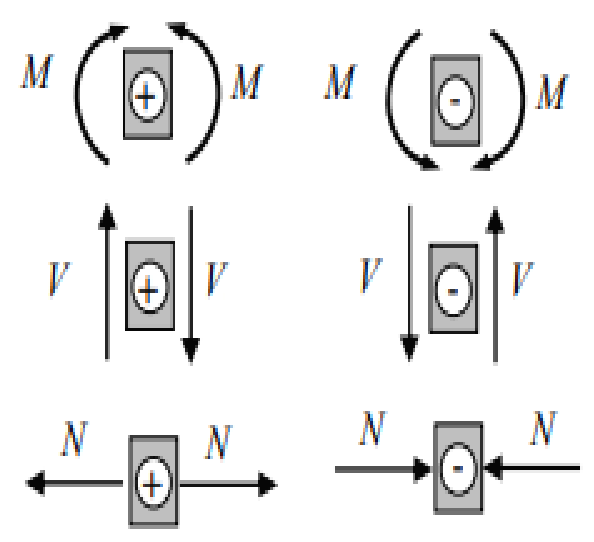

Fig. 3 Sign convention of cross-sectional forces

Under planar loading, we denote the internal forces by 
capital letters without indices.

\section{DIFFERENTIAL RELATION}

There is a differential relation between internal forces invented by Schwedler [12].

We now derive it on a small differential element, which we select from the beam, Fig. 4.
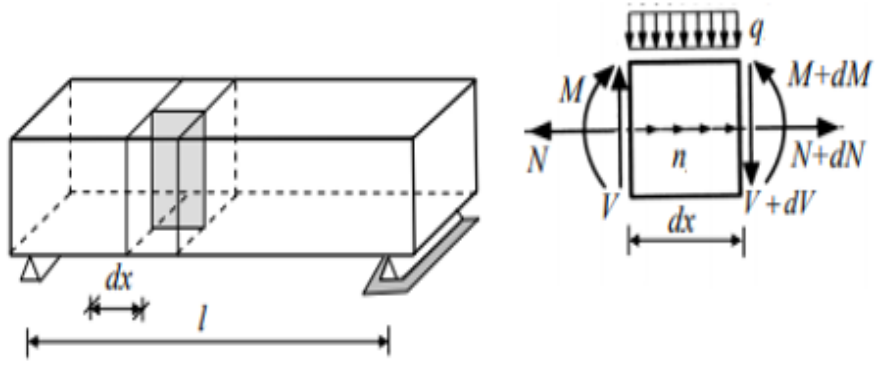

Fig. 4 Differential element selected from the beam

We consider a statically determined beam, loaded by any continuous transversal load and singular forces and couples. At point $\mathrm{x}$ we cut a differential element of length $\mathrm{dx}$ with two parallel sections perpendicular to the longitudinal beam axis (Fig. 4). Since this is a functional dependence in the following formulas, the load and internal forces depend on $\mathrm{x}$. The following loads act on the section $\mathrm{dx}$ of the straight beam:

- uniform continuous vertical load of intensity $\mathrm{q}(\mathrm{x})$,

- uniform continuous axial load of intensity $\mathrm{n}(\mathrm{x})$.

The internal forces $\mathrm{N}(\mathrm{x}), \mathrm{V}(\mathrm{x}), \mathrm{M}(\mathrm{x})$ act at the point $\mathrm{x}$ on the differential element, and at the point $\mathrm{x}+\mathrm{dx}$ the internal forces $\mathrm{N}(\mathrm{x})+\mathrm{dN}(\mathrm{x}), \mathrm{V}(\mathrm{x})+\mathrm{dV}(\mathrm{x}), \mathrm{M}(\mathrm{x})+\mathrm{dM}(\mathrm{x})$. We compile following three conditions of equilibrium, namely:

$\sum F_{x}=0$

$-N(x)+n(x) d x+[N(x)+d N(x)]=0$

$\sum F_{z}=0$

$-V(x)+q(x) d x+[V(x)+d V(x)]=0$

(2)

$$
\begin{aligned}
& \sum_{M(x)+V(x) d x-q(x) d x \frac{d x}{2}-[M(x)+d M(x)]=0}
\end{aligned}
$$

By modifying equations (1) - (2), we obtain the following relations:

$$
\begin{aligned}
& \frac{d N(x)}{d x} \\
& =-n(x)
\end{aligned}
$$

$\frac{d V(x)}{d x}$

$=-q(x)$

In Eq.3, we neglect the product $q d x \frac{d x}{2}$, which is significantly smaller compared to the other terms, and we get the relation:

$\frac{d M(x)}{d x}$
$=V(x)$

Eq. 6 represents the known Schwedler theorem [1215]: The first derivative of the bending moment with respect to the independent variable $\mathrm{x}$ is the shear force.

If we substitute relation 5 into relation 6 , we get relation 7 , which expresses the differential dependence between the bending moment and the transversal load.

$$
\begin{aligned}
& \frac{d^{2} M(x)}{d x^{2}} \\
& =-q(x)
\end{aligned}
$$

By Integrating Eqs.(4) - (6) we obtain functional relation of internal forces:

$$
\begin{gathered}
\int_{x_{0}}^{x} d N(x)=-\int_{x_{0}}^{x} n(x) d x \\
N(x)=-\int_{x_{0}}^{x} n(x) d x \\
+N\left(x_{0}\right) \\
\int_{x_{0}}^{x} d V(x)=-\int_{x_{0}}^{x} q(x) d x \\
V(x)=-\int_{x_{0}}^{x} q(x) d x \\
+V\left(x_{0}\right)
\end{gathered}
$$

$$
\begin{aligned}
& \int_{x_{0}}^{x} d M(x)=\int_{x_{0}}^{x} V(x) d x \\
& M(x)=\int_{x_{0}}^{x} V(x) d x+M\left(x_{0}\right)
\end{aligned}
$$




$$
\begin{gathered}
M(x)=-\iint_{x_{0}}^{x} q(x) d x d x+V\left(x_{0}\right) x \\
+M\left(x_{0}\right)
\end{gathered}
$$

In Eqs.(8) - (10) the values of forces in $\mathrm{x}=\mathrm{x}_{0}$ act in the origin of the integrating section.

\section{DETERMINATION OF THE COURSE OF INTERNAL FORCES}

We will only consider vertical loads. Assume a continuous trapezoidal load on the section $\left\langle\mathrm{x}_{\mathrm{z}}, \mathrm{x}_{\mathrm{k}}\right\rangle$, (Fig. $5)$. The functional relation of this load is derived from the directional equation of straight line (11).

$q(x)$

$=k x+q$

Where $\mathrm{k}$ is the direction of the line and $\mathrm{q}$ is the value of the load at the beginning. In accordance with Fig. 5, we rewrite equation (11) to the following form:

$q(x)$

$=\frac{q_{k}-q_{z}}{x_{k}-x_{z}} x+q_{z}$

Where the direction of the line $k$ is defined by to the following relation

$$
\stackrel{k}{=} \frac{q_{k}-q_{z}}{x_{k}-x_{z}}
$$

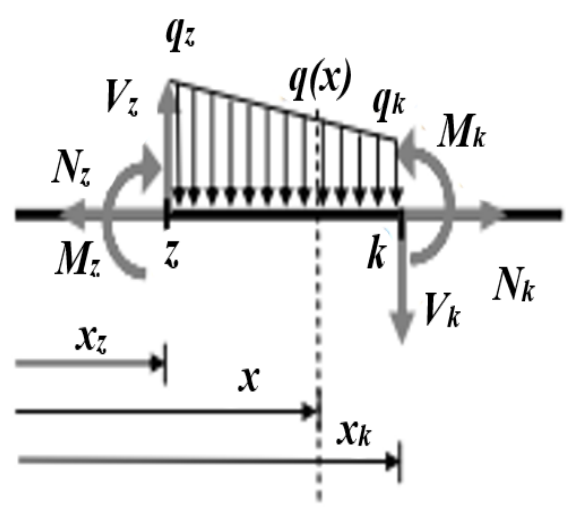

Fig. 5 Section $\mathrm{z}-\mathrm{k}$ of the beam loaded by the trapezoidal load

$V(x)=V_{z}-\int_{x_{z}}^{x}\left[\frac{q_{k}-q_{z}}{x_{k}-x_{z}} x+q_{z}\right] d x$

$$
\begin{aligned}
V(x)= & V_{z}-q_{z}\left(x-x_{z}\right) \\
& \quad-\frac{q_{k}-q_{z}}{x_{k}-x_{z}} \frac{\left(x-x_{z}\right)^{2}}{2} \\
M(x)= & M_{z}-\iint_{x_{z}}^{x}\left[\frac{q_{k}-q_{z}}{x_{k}-x_{z}} x+q_{z}\right] d x d x \\
& M(x) \\
= & M_{z}+V_{z}\left(x-x_{z}\right)-q_{z} \frac{\left(x-x_{z}\right)^{2}}{2} \\
- & \frac{q_{k}-q_{z}}{x_{k}-x_{z}} \frac{\left(x-x_{z}\right)^{3}}{6}
\end{aligned}
$$

According to the above formula (12), we can determine the load on the beam. The integration coefficients $\mathrm{V}_{\mathrm{z}}$ and $\mathrm{M}_{\mathrm{z}}$ are them determined from the boundary conditions.

Let us assume a simple beam loaded with a trapezoidal load along its entire length according to (Fig. 6). The solution of this example is done in SMath Studio.
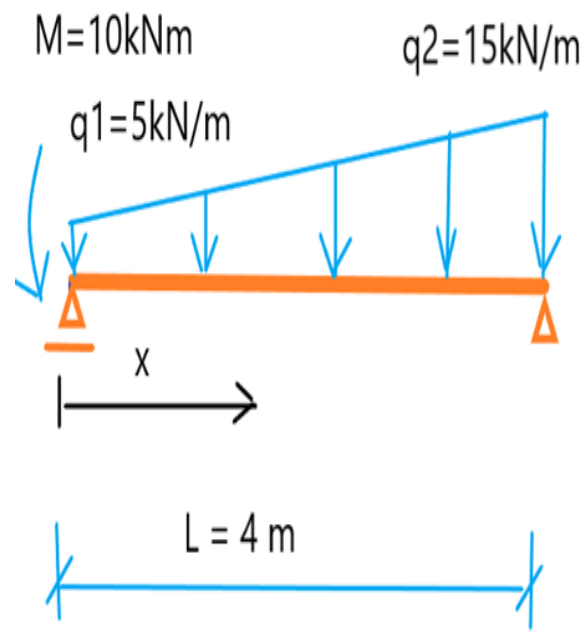

Fig. 6 Simple beam loaded by the trapezoidal load

First of all, we define the input data for solving the given problem: $\mathrm{q}_{\mathrm{z}}$ - represents the value of continuous load at the beginning of the beam, $\mathrm{q}_{\mathrm{k}}$ - represents the value of continuous load at the end of the beam, $\mathrm{M}_{\mathrm{z}}$ represents the value of singular moment at the beginning of the beam, $M_{k}$ - represents the value of singular moment at the end of the beam and L - is the total length of the beam on which the trapezoidal load acts. The performance from the program is shown in Fig. 7. 
Calculation of internal forces on a beam loaded with a trapezoidal load

$$
\text { Input: } \begin{aligned}
& q_{z_{-}}:=5 \mathrm{kN} \mathrm{m}^{-1} \\
& q_{k_{-}}:=15 \mathrm{kN} \mathrm{m}^{-1} \\
& M_{z_{-}}:=-10 \mathrm{kN} \mathrm{m} \\
& M_{k_{-}}:=0 \mathrm{kN} \mathrm{m} \\
& L_{-}:=4 \mathrm{~m}
\end{aligned}
$$

Fig. 7 Input data of the problem

In the Smath Studio program, for further calculation, for the sake of simplicity, we will remove the physical units by dividing them by the appropriate physical quantity of each input value. The whole procedure is shown in Fig. 8.

\section{Removal of physical units:}

$$
\begin{array}{ll}
q_{z}:=\frac{q_{z_{-}}}{\mathrm{kN} \mathrm{m}} \quad q_{k}:=\frac{q_{k_{-}}}{\mathrm{kN} \mathrm{m}-1} \\
M_{z}:=\frac{M_{z_{-}}}{\mathrm{kN} \mathrm{m}} \quad M_{\mathrm{k}}:=\frac{M_{\mathrm{k}_{-}}}{\mathrm{kN} \mathrm{m}} \\
L:=\frac{L}{\mathrm{~m}} &
\end{array}
$$

Fig. 8 Removal of physical units

In the next step, the direction of the straight-line $k$ is calculated according to Equation (13) for the given trapezoidal load and the load itself $\mathrm{q}(\mathrm{x})$ according to Equation (12), where $\mathrm{x}_{\mathrm{z}}=0$ and $\mathrm{x}_{\mathrm{k}}=\mathrm{L}$ (Fig. 6).

$$
\begin{array}{ll}
\text { Gradient of a line: } \quad & k:=\frac{q_{k}-q_{z}}{L} \\
& k=\frac{5}{2} \\
\text { Load funkcion: } & q(x):=q_{z}+k \cdot x \\
& q(x)=\frac{5 \cdot(2+x)}{2}
\end{array}
$$

Fig. 9 Function of trapezoidal load

The functional relation of the shear forces is expressed based on the integration of the specified load (Fig. 10) and the functional relation of the bending moments is obtained by integrating the shear forces (Fig. 11).
Shear force function:

$$
\begin{aligned}
& \text { integral }_{q}:=\operatorname{maple}\left(\int_{0}^{x}-q(x) d x\right)=-\frac{5 \cdot x \cdot(4+x)}{4} \\
& V(x):=\text { integral }_{q}+A=-\frac{-4 \cdot A+5 \cdot x^{2}+20 \cdot x}{4}
\end{aligned}
$$

Fig. 10 Functional expression of shear forces

$$
\begin{aligned}
& \text { Bending moment function: } \\
& \text { integral }_{V}:=\operatorname{maple}\left(\int_{0}^{x} V(x) d x\right)=-\frac{x \cdot\left(-12 \cdot A+5 \cdot x^{2}+30 \cdot x\right)}{12} \\
& M(x):=\text { integral }_{V}+B \\
& M(x)=-\frac{6 \cdot\left(-2 \cdot B+5 \cdot x^{2}\right)+5 \cdot x^{3}-12 \cdot A \cdot x}{12}
\end{aligned}
$$

Fig. 11 Functional expression of bending moments

\section{Boundary conditions:}

a)

$$
\begin{aligned}
& \mathbf{M}(0)=\mathbf{M z} \\
& M(0)=B \quad B:=M_{z} \quad B=-10
\end{aligned}
$$

b) $\quad M(L)=M k$ :

$$
\begin{aligned}
& M(L)=\frac{2 \cdot(-40+3 \cdot(-25+2 \cdot A))}{3} \\
& M(0)=-10 \\
& A:=\operatorname{solve}(M(L)=0 ; A)=19,16667 \\
& A=\frac{95833333333333}{5000000000000}
\end{aligned}
$$

Fig. 12 Calculation of integrating coefficients

The integration coefficients are obtained by using the boundary conditions on the given beam. In our case we have a given simple beam and therefore the moment at the beginning of the beam $\mathrm{M}_{\mathrm{z}}=-\mathrm{M}=-10 \mathrm{kNm}$ singular moment and moment at the end of the beam $\mathrm{M}_{\mathrm{k}}=0 \mathrm{kNm}$ (Fig.6). The solution in the SMath studio program is shown in Fig. 12, the boundary conditions being specified:

a) at the beginning of the beam, and

b) at the end of the beam.

The integration coefficient $\mathrm{A}=19.16667 \mathrm{kN}$ represents both the shear force at the beginning of the beam and thus also the reaction in the support at the beginning of the beam and the integration coefficient $\mathrm{B}$ is the bending moment at the beginning of the beam also in terms of formulas (9) and (10).

Finally, we can write a functional expression of the load and internal forces, as shown in Fig.13. For the 
functional expression of internal forces, the integration coefficient is set in fractional form.

\section{Functions of Load, Shear force and Bending moment:}

$$
\begin{aligned}
& q(x)=\frac{5 \cdot(2+x)}{2} \\
& V(x)=-\frac{-\frac{95833333333333}{1250000000000}+5 \cdot x^{2}+20 \cdot x}{4} \\
& M(x)=\frac{-10 \cdot\left(24+x^{3}+6 \cdot x^{2}\right)+\frac{2874999999999990}{6250000000000} \cdot x}{24}
\end{aligned}
$$

Fig. 13 Functional expression of loads and crosssectional forces

The following diagrams (Fig.14, Fig.15, and Fig.16) show the functions presented in Fig.13. Fig.14 is a course of the trapezoidal load q(x), Fig.15 is a course of shear forces $V(x)$ and Fig.16 is a course of bending moments $\mathrm{M}(\mathrm{x})$ along the entire length of the beam $\mathrm{L}$.

The course of $\mathrm{M}(\mathrm{x})$ on a simple beam loaded with a trapezoidal continuous load $\mathrm{q}(\mathrm{x})$ according to the diagram from Fig.6 is shown in Fig.16. Due to convention, used in civil engineering, this graph is drawn with a mirror image with regards to the horizontal axis.

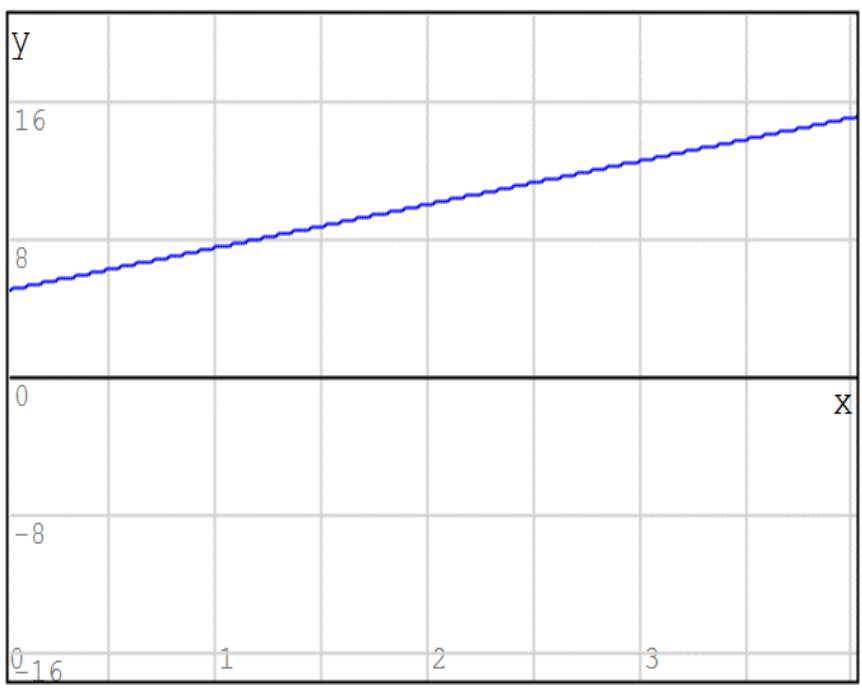

$q(x)$

Fig. 14 Course of load q(x)

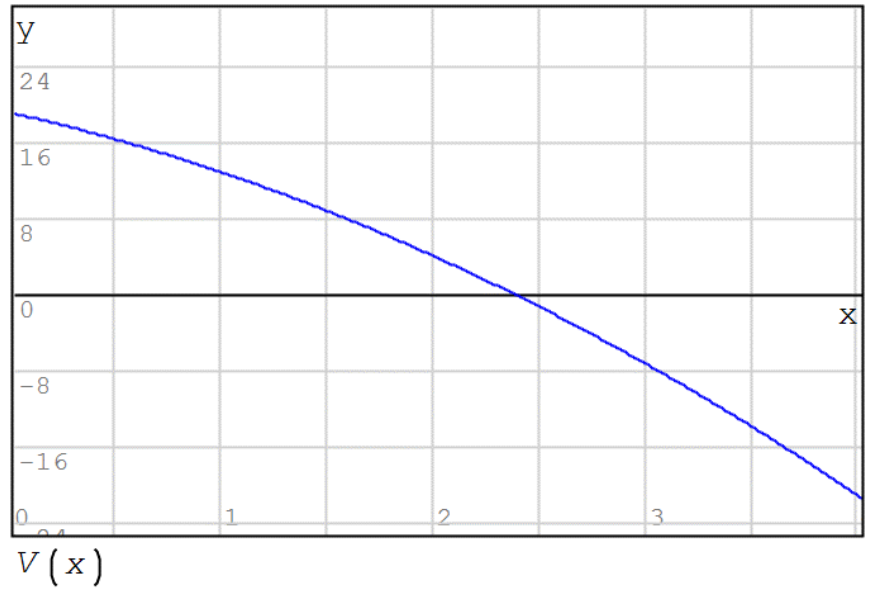

Fig. 15 Shear force diagram $\mathrm{V}(\mathrm{x})$

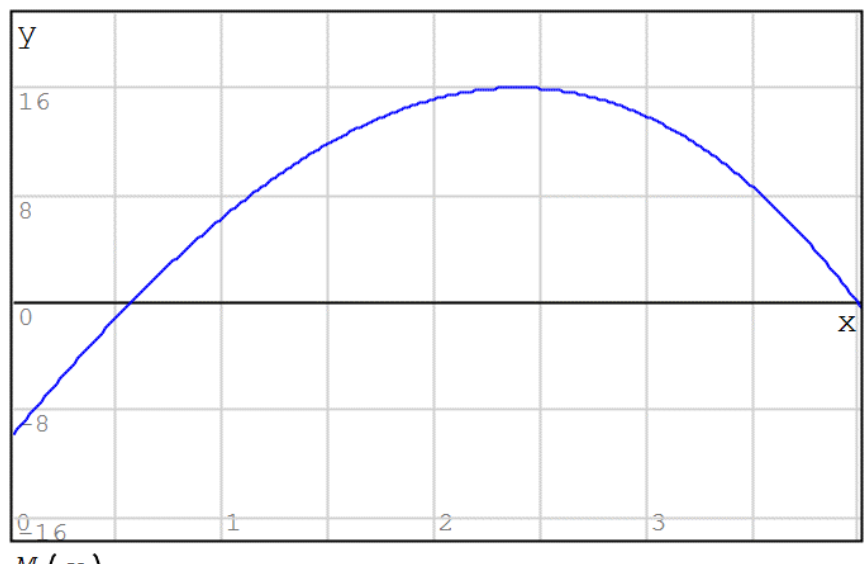

$M(\mathrm{x})$

Fig. 16 Bending moment diagram $\mathrm{M}(\mathrm{x})$

\section{DEFLECTION LINE OF THE BEAM}

Consider a beam loaded in the $\mathrm{x}-\mathrm{z}$ plane. As a result of this load, the originally straight axis of the beam lying in the x-axis is deformed into a planar curve, Fig.17. This deformed axis (due to the load) is called the deflection line of the beam [16-18].

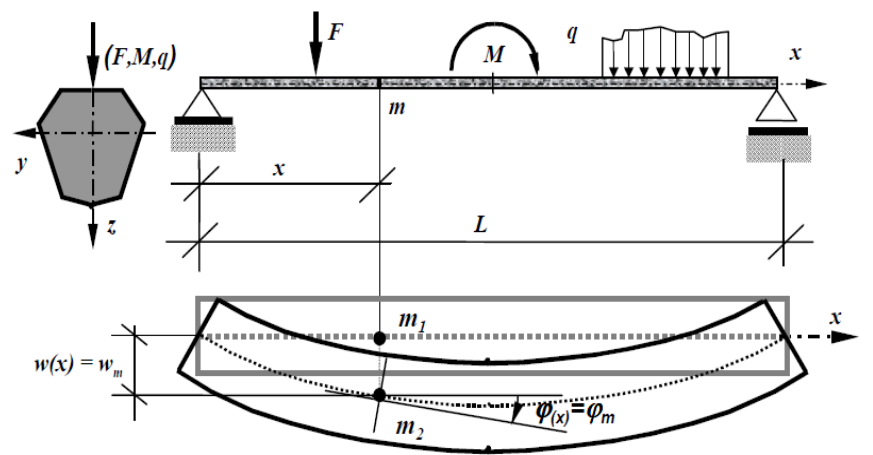

Fig. 17 Bending of the beam [16] 
In civil engineering practice, for most beams, the maximum value of the vertical deflection $\mathrm{w}_{\max }$ is very small and the angles of the tangent lines of the beam are also small.

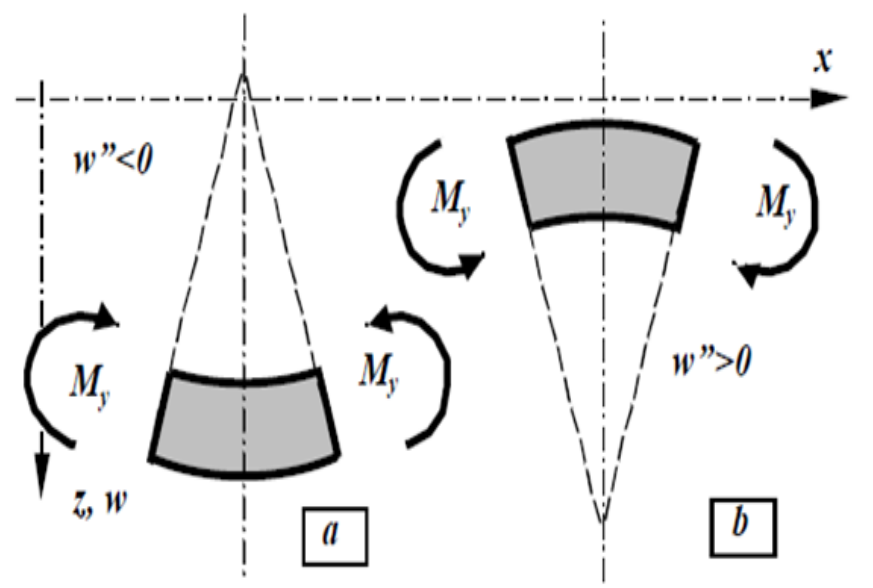

Fig. 18 Bending of the differential element [16]

We usually assume that

$$
\begin{gathered}
w_{\max }<\frac{L}{300}, \quad \frac{d w_{\max }}{d x} \\
<\frac{\pi}{60}
\end{gathered}
$$

Then we talk about beams with small deflections, and it can be proved that the horizontal components of the displacement on the central axis are practically zero.

In our chosen coordinate system shown in Fig.18, the relationship for single bend curvature holds:

$$
\begin{aligned}
& \frac{1}{\varrho(x)} \\
& =\frac{\frac{d^{2} w(x)}{d x^{2}}}{\left[1+\left(\frac{d w(x)}{d x}\right)^{2}\right]^{\frac{3}{2}}}
\end{aligned}
$$

The curvature based on the derivation from the simple bending of the beam in general cross-section $\mathrm{x}$ can be written in the form 18 :

$$
\begin{aligned}
& \frac{1}{\varrho(x)} \\
& =-\frac{M(x)}{E I_{y}(x)}
\end{aligned}
$$

Since we consider small deformations, the derivative of the deflection under assumption (16) according to $\mathrm{x}$ raised to the second order given in the denominator in relation (17) is small, so we can neglect it. Then expression (17) in conjunction with expression (18) can be rewritten into the following relation [17].

$$
\begin{aligned}
& \frac{d^{2} w(x)}{d x^{2}} \\
& =-\frac{M(x)}{E I_{y}(x)}
\end{aligned}
$$

Equation (19) is the known differential equation of the deflection line of a beam, where $\mathrm{E}$ is the Young's modulus of elasticity of the material from which the beam is made and $I_{y}$ is the moment of inertia of the cross-section.

By the first integration of the relation (19) we obtain the function of rotation (20) and by the second integration the function of deflection (21).

$$
\begin{aligned}
& \varphi(x)=\frac{d w(x)}{d x}=\varphi\left(x_{0}\right) \\
& -\int_{x_{0}}^{x}\left[\frac{M(x)}{E I_{y}(x)}\right] d x \\
& \mathrm{w}(x)=\int_{x_{0}}^{x} \varphi(x) d x \\
& =w\left(x_{0}\right)+\varphi\left(x_{0}\right) x \\
& -\iint_{x_{z}}^{x}\left[\frac{M(x)}{E I_{y}(x)}\right] d x d x
\end{aligned}
$$

The integration coefficients $w\left(x_{0}\right)$ and $\varphi\left(x_{0}\right)$ represent the rotation and deflection at the beginning of the integration section and we obtain them from the boundary conditions reflecting the beam supports, or the conditions of continuity of deformations at the boundaries of two adjacent sections.

If we integrate equation (19) twice according to $\mathrm{x}$ and substitute (7) into it, we obtain the differential equation of the deflection line of the beam in a modified form.

$$
\begin{aligned}
& \frac{d^{4} w(x)}{d x^{4}} \\
& =\frac{q(x)}{E I_{y}(x)}
\end{aligned}
$$

\section{DETERMINATION OF DEFLECTION LENES}

Let us consider a beam, with a constant Young's modulus of elasticity $\mathrm{E}$ and a moment of inertia $\mathrm{I}_{\mathrm{y}}$ along 
the entire length of the beam. In case of a trapezoidal load, the deformation functions according to equations (20), (21) and (15) will be determined as follows:

$$
\begin{gathered}
E I_{y} \varphi(x)=\varphi\left(x_{0}\right)-\int_{x_{0}}^{x}\left[M_{z}+V_{z}\left(x-x_{z}\right)\right] d x \\
-\int_{x_{0}}^{x}\left[-q_{z} \frac{\left(x-x_{z}\right)^{2}}{2}\right. \\
\left.-\frac{q_{k}-q_{z}}{x_{k}-x_{z}} \frac{\left(x-x_{z}\right)^{3}}{6}\right] d x \\
-\int_{x_{0}}^{x} \int_{x_{0}}^{x}\left[M_{z}+V_{z}\left(x-x_{z}\right)-q_{z} \frac{\left(x-x_{z}\right)^{2}}{2}\right] d x d x \\
-\int_{x_{0}}^{x} \int_{x_{0}}^{x}\left[-\frac{q_{k}-q_{z}}{x_{k}-x_{z}} \frac{\left(x-x_{z}\right)^{3}}{6}\right] d x d x
\end{gathered}
$$

When calculating deformations, it is necessary to define the material properties from which the beam is made, in our case of concrete. The Young's modulus of elasticity $\mathrm{E}$ is $20 \mathrm{GPa}$.

$$
\begin{array}{ll}
\text { Input: } & E_{-}:=20 \mathrm{GPa} \\
& b:=150 \mathrm{~mm} \\
& h:=250 \mathrm{~mm} \\
& W_{z}:=0 \\
W_{k}:=0 \\
I_{-}:=\frac{1}{12} \cdot b \cdot h^{3}=1,9531 \cdot 10^{-4} \mathrm{~m}^{4}
\end{array}
$$

Fig. 19 Input data for deflection line determination

The cross section of the beam is constant along entire its length, the width $\mathrm{b}$ is $150 \mathrm{~mm}$, and the depth $\mathrm{h}$ is 250 $\mathrm{mm}$. The input data required for the calculation of deformations are shown in the previous Fig. 19.

$$
\begin{aligned}
& \text { Removal of physical units: } \\
& \qquad E:=\frac{E}{\mathrm{kPa}} \quad I:=\frac{I}{\mathrm{~m}}
\end{aligned}
$$

Fig. 20 Removal of physical units

\section{Slope function:}

$$
\begin{aligned}
& \text { integral }_{M}:=\operatorname{maple}\left(\int_{0}^{x}-M(x) \mathrm{d} x\right) \\
& \varphi(x):=\frac{1}{E \cdot I} \cdot\left(\text { integral }_{M}+C\right)
\end{aligned}
$$

Fig. 21 Determination of slope function

$$
\begin{aligned}
& \text { Deflection function: } \\
& \text { integral } \left._{\varphi}:=\operatorname{maple}_{0}^{\mathrm{x}} \varphi(x) \mathrm{d} x\right) \\
& \mathrm{W}(\mathrm{x}):=\text { integral }_{\varphi}+D
\end{aligned}
$$

Fig. 22 Determination of deflection line function

\section{Boundary conditions:}

c)

$$
\begin{aligned}
& \mathbf{w}(\mathbf{0})=\mathbf{0}, \\
& W(0)=D \quad D:=W_{z} \quad D=0 \\
& \mathbf{w}(\mathbf{L})=0, \\
& C:=\operatorname{solve}(w(L)=0 ; C)=\frac{62222222222221}{5000000000000}
\end{aligned}
$$$$
\text { d) } \quad \mathrm{w}(\mathrm{L})=0 \text {, }
$$

Fig. 23 Determination of integration coefficients

The integration coefficients given in the functional expression of the rotation (Fig.21) and the deflections (Fig.22) are determined by the supports of the beam. At the beginning of the beam (Fig.6) there is a sliding hinge support and at the end of the beam there is a hinge support. In both cases it is a hinge and therefore the deflection at these points is equal to zero.

The calculated integration coefficient C (Fig.23) represents the rotation $\varphi\left(\mathrm{x}_{0}\right)$ at the beginning of the beam (23) and it can also be seen in Fig.24. The integration coefficient D (Fig.23) is the deflection $\mathrm{w}\left(\mathrm{x}_{0}\right)$ at the beginning of the beam (24) and Fig.25.

The resulting deflection curves are shown in Fig.24 and Fig. 25. 


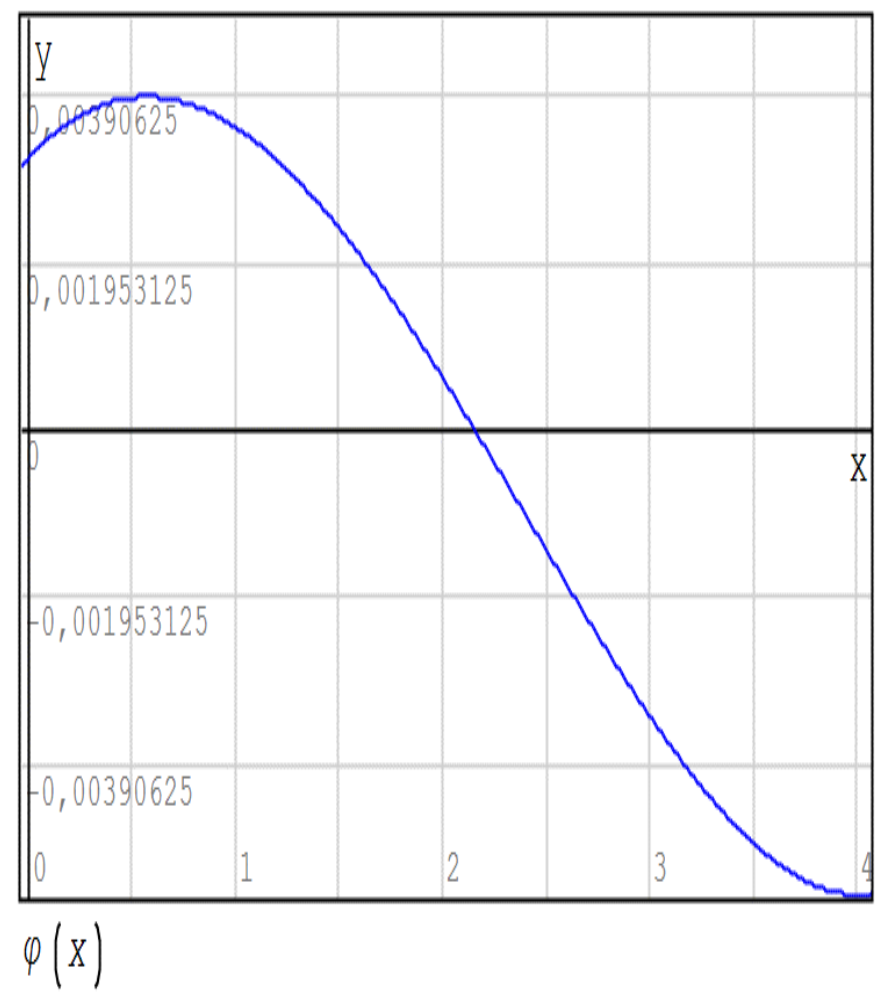

Fig. 24 Course of rotations in solved beam

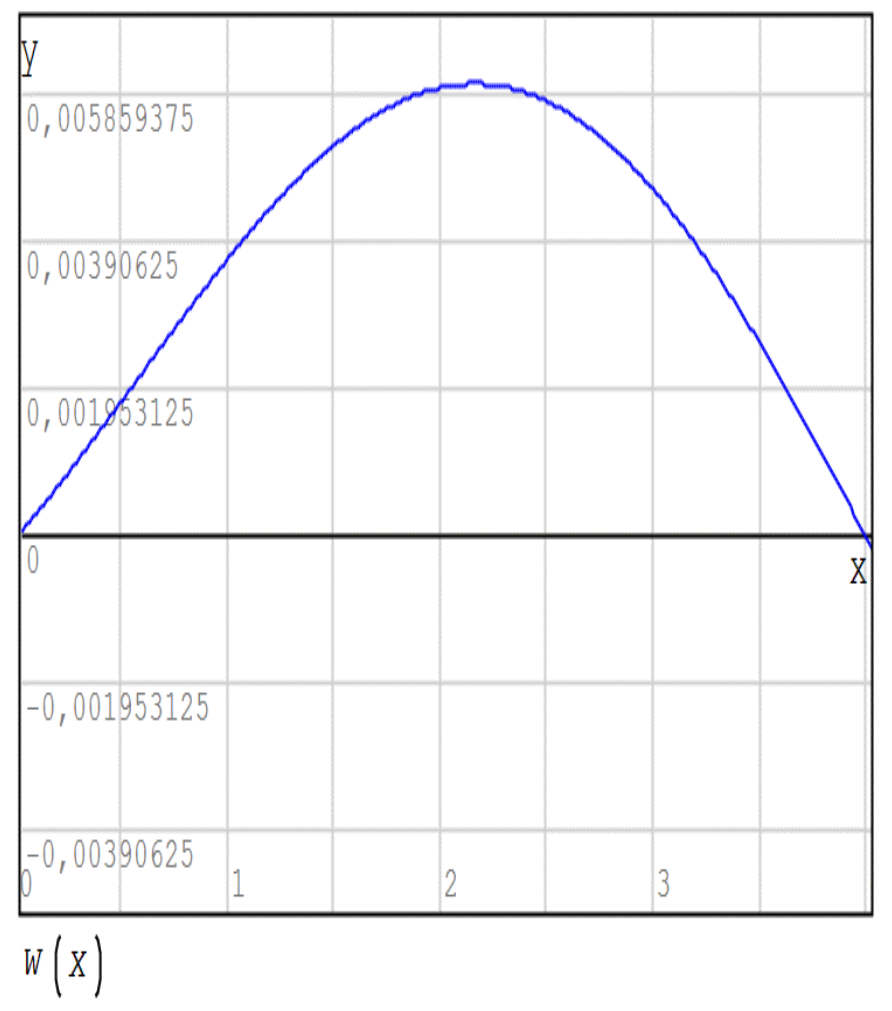

Fig. 25 Course of deflections in solved beam

Basic procedures for working with the mathematical program Smath studio are also given in the publication
[19], support for this program is also available on the website [20].

\section{SUMMARY}

The paper describes one of possible ways for automating calculations in statics using SMath Studio. A procedure for the calculation of internal forces and deformations on a simple beam loaded with a trapezoidal load are provided.

To solve the given task, a theoretical procedure is taken, which can be used for automating calculations in SMath studio. When determining internal forces, Schwedler's theorems is used to help us with treating the internal forces on a loaded beam. The expression of shear forces $\mathrm{V}(\mathrm{x})$, bending moments $\mathrm{M}(\mathrm{x})$ and trapezoidal load $\mathrm{q}(\mathrm{x})$ is in a functional form and thanks to that it is possible to plot their courses perfectly. In addition to the internal forces on the specified beam, the procedure for solving deformations based on the bending line of the beam is given. From this, relations to the slope and deflection of the beam can be derived by integration. These relationships use derivatives to link the deformation of the beam with the rotation and the bending moment. In addition to the possibility of tasks automating in the SMath studio program, the repeated integrals for solving internal forces and deformations can be used in civil engineering practice. Even monitoring of students' knowledge in similar programs, as well as e.g. Mathcad can be found in [21].

\section{CONCLUSION}

The presented work introduces a new methodology for teaching of the bending of beams. In comparison to classical teaching, where the student has to cope with the complex issues of internal forces, boundary conditions and deformation of beam in one example, the introduced way of teaching offers an alternative option involving computer and the mathematical program Smath studio. Within it, the student not sees not only all equations (as if he wrote them classically), but he has the graphical outputs displayed automatically, involving individual quantities on particular intervals. By following variations of individual input parameters, he can capture their effect on the overall tensity and deformation of the system. In contrast to classical computer methods (FEM), which offer input-output solutions without the possibility of monitoring the sequence of calculations, during such exercises the mathematical program allows students to fix causal relationships, using a mathematical expression. 


\section{ACKNOWLEDGMENT}

The work has been supported by the grant from Slovak Grant Agency VEGA, Registration No. 1/0412/18.

\section{REFERENCES}

[1] Z. Kala, A. Omishore, "Fuzzy stochastic approaches for analysing the serviceability limit state of load bearing systems," International journal of mathematical models and methods in applied siences, vol. 10, 2016, pp.294-301.

[2] K. Kotrasova, E. Kormanikova, "A case study on seismic behavior of rectangular tanks considering fluid - structure interaction," International journal of mechanics, vol. 10, 2016, pp. $242-252$.

[3] Z. Kala, M. Kalina, "Static Equilibrium States of Von Mises Trusses," International journal of mechanics, vol. 10, 2016, pp. $294-298$.

[4] L. Wu., D. Wang, Y. Zhu., et al. "A study on the effects of hydraulic static load on the dynamic characteristics of the partially liquid-filled cylindrical shell," Journal of fluids and structures, vol. 85, 2019, pp 40-54.

[5] S. Radaev, "Numerical and analytical modeling of permanent deformations in panels made of nanomodified carbon fiber reinforced plastic with asymmetric packing," International journal of mechanics, vol. 15, 2021, pp. $172-180$.

[6] H. Daou, W. Raphael, "Comparison between various creep calculation methods for the time-dependent analysis of terminal 2E at roissy," Jordan Journal of Civil Engineering, 2021, vol. 15, no. 1, pp. 64-76.

[7] M. Barski, A. Stawiarski, P. J. Romanowicz, B. Szybiński, "Local elasto-plastic buckling of iIsotropic plates with cutouts under tension loading conditions," International journal of mechanics, vol. 15, 2021, pp. $69-87$.

[8] E. Kormanikova, K. Kotrasova, "Sizing optimization of sandwich plate with laminate faces," International journal of mathematics and computers in simulation, vol. 10, 2016, pp. $273-280$.
[9] N. Ramesh, P. Kuklik, M. Valek, "Several comments on numerical modeling of shallow foundations," Procedia Engineering, 2017, 195, pp 73-80.

[10] H. Elhuni, D. Basu, "Dynamic soil structure interaction model for beams on viscoelastic foundations subjected to oscillatory and moving loads," Computers and geotechnics, 2019, vol. 115.

[11] Smath Studio, https://en.smath.com/view/ SMathStudio /summary

O. Hubová, Z. Mistríková, Y. Koleková, Engineering statics, 2017, Spektrum STU (in Slovak)

[12] J. W. Schwedler, "Theorie der Brückenbalkensysteme". Zeitschrift für Bauwesen. 1851, vol. 1, (3-4), pp. 114-123

[13] S. D. Sheppard, Statics, 2007, John Wiley \& Sonc Inc

[14] J. Bolcek, Evaluation of accuracy of shear formula for chosen shapes of beam, Bachelor's thesis, Brno, 2019 (in Czech)

[15] J. Dický, Z. Mistríková, J. Sumec, Elasticity and rigidity in civil engineering 1,2010 , Publisher STU (in Slovak)

[16] J. Dický, L. Prekop, K. Tvrdá, Elasticity and rigidity, Exercise aid, 2016, Publisher STU (in Slovak)

[17] J. M. Gere, B. J. Goodno, Mechanics of materials, $7^{\text {th }}$ edition, 2009, Cengage learning

[18] B. V. Liengme, SMath for Physics, A primer, 2015, Morgan \& Claypool Publishers,

[19] Smath Studio Forum, https://en.smath.com/forum/

[20] M. Batova, "Automation of monitoring students' knowledge and independent work using Mathcad," International journal of education and information technologies, vol. 14, 2020, pp.172-181. 
K. Tvrdá graduated at the Faculty of Civil Engineering Slovak Technical University in Bratislava, study program - Building Construction and Architecture, specialization - Statics of building structures. Since 2014 she has work at Slovak Technical University in Bratislava, Faculty of Civil Engineering, Department of Structural Mechanics as associate professor.

Her scientific field is optimization and reliability of building structures and optimization of structural elements and structures on a flexible and inelastic base, numerical methods in mechanics and creation of mathematical models.

Her teaching: Static Analysis of the Structures, Elasticity, FEM in statics and others.
Creative Commons Attribution License 4.0 (Attribution 4.0 International, CC BY 4.0)

This article is published under the terms of the Creative Commons Attribution License 4.0

https://creativecommons.org/licenses/by/4.0/deed.en_US 